Old Dominion University

ODU Digital Commons

\title{
Interaction Between Air Plasma-Produced Aqueous 102 and the Spin Trap DMPO in Electron Spin Resonance
}

\author{
Chen Chen \\ Old Dominion University \\ Fanying Li \\ Old Dominion University \\ Hai-Lan Chen \\ Old Dominion University, h1chen@odu.edu \\ Michael G. Kong \\ Old Dominion University, mkong@odu.edu
}

Follow this and additional works at: https://digitalcommons.odu.edu/bioelectrics_pubs

Part of the Plasma and Beam Physics Commons

\section{Original Publication Citation}

Chen, C., Fanying, L., Hai-Lan, C., \& Kong, M. G. (2017). Interaction between air plasma-produced aqueous

${ }^{1} \mathrm{O}_{2}$ and the spin trap dmpo in electron spin resonance. Physics of Plasmas, 24(10), 103501. doi:10.1063/ 1.4986008

This Article is brought to you for free and open access by the Frank Reidy Research Center for Bioelectrics at ODU Digital Commons. It has been accepted for inclusion in Bioelectrics Publications by an authorized administrator of ODU Digital Commons. For more information, please contact digitalcommons@odu.edu. 


\section{Interaction between air plasma-produced aqueous ${ }^{1} \mathrm{O}_{2}$ and the spin trap DMPO in electron spin resonance}

Chen Chen, Fanying Li, Hai-Lan Chen, and Michael G. Kong

Citation: Physics of Plasmas 24, 103501 (2017); doi: 10.1063/1.4986008

View online: http://dx.doi.org/10.1063/1.4986008

View Table of Contents: http://aip.scitation.org/toc/php/24/10

Published by the American Institute of Physics

\section{Articles you may be interested in}

Plasma-based water purification: Challenges and prospects for the future

Physics of Plasmas 24, 055501 (2017); 10.1063/1.4977921

Perspective: The physics, diagnostics, and applications of atmospheric pressure low temperature plasma sources used in plasma medicine

Journal of Applied Physics 122, 020901 (2017); 10.1063/1.4993710

Investigation on the energy spectrums of electrons in atmospheric pressure argon plasma jets and their dependences on the applied voltage

Physics of Plasmas 24, 083509 (2017); 10.1063/1.4986145

Uniformity optimization and dynamic studies of plasma jet array interaction in argon

Physics of Plasmas 24, 093507 (2017); 10.1063/1.4998469

Plasma-induced flow instabilities in atmospheric pressure plasma jets

Applied Physics Letters 111, 114101 (2017); 10.1063/1.4996192

Dynamics of apokamp-type atmospheric pressure plasma jets initiated in air by a repetitive pulsed discharge

Physics of Plasmas 24, 043514 (2017); 10.1063/1.4981385

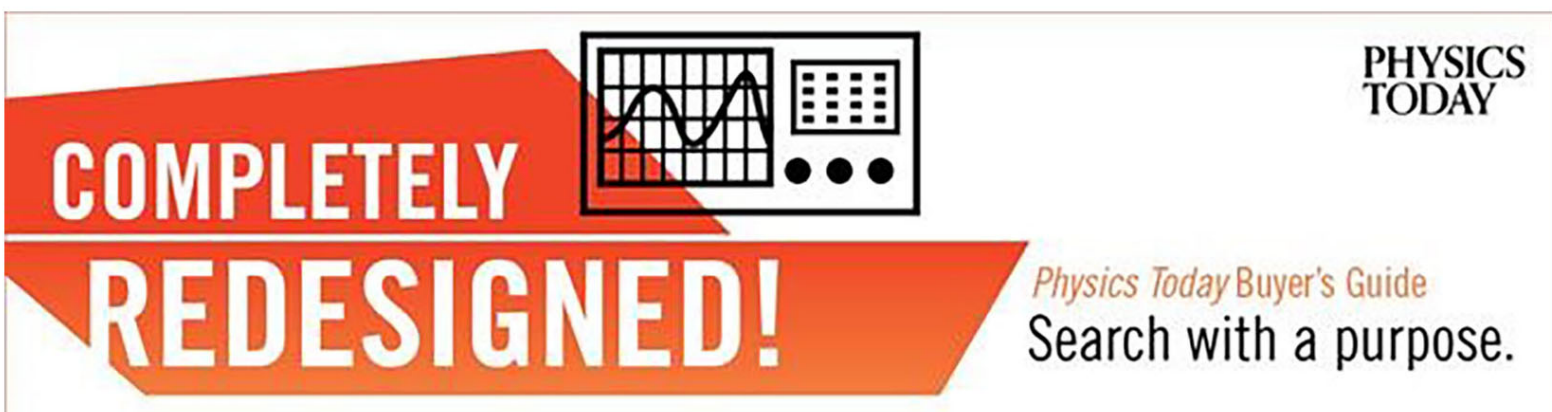




\title{
Interaction between air plasma-produced aqueous ${ }^{1} \mathrm{O}_{2}$ and the spin trap DMPO in electron spin resonance
}

\author{
Chen Chen, ${ }^{1,2, a)}$ Fanying Li, ${ }^{2}$ Hai-Lan Chen, ${ }^{2}$ and Michael G. Kong ${ }^{1,2,3, a)}$ \\ ${ }^{1}$ State Key Laboratory of Electrical Insulation and Power Equipment, Center for Plasma Biomedicine, \\ Xi' an Jiaotong University, Xi' an, Shaanxi 710049, People's Republic of China \\ ${ }^{2}$ Frank Reidy Center for Bioelectrics, Old Dominion University, Norfolk, Virginia 23508, USA \\ ${ }^{3}$ Department of Electrical and Computer Engineering, Old Dominion University, Norfolk, Virginia 23529, \\ USA
}

(Received 28 May 2017; accepted 23 August 2017; published online 12 September 2017)

A series of electron spin resonance (ESR) experiments is done to quantitatively measure the concentrations of aqueous ${ }^{1} \mathrm{O}_{2}$ and $\mathrm{OH}$ produced by a surface micro-discharge air plasma device. ${ }^{1} \mathrm{O}_{2}$ is tested to be existed in the plasma treated solution by using the spin trap of TEMP. However, the unexpected DMPOX spectrum is observed in measuring $\mathrm{OH}$ by the spin trap of 5,5-Dimethyl1-Pyrroline-N-Oxide (DMPO). With more chemical scavenger experiments, it is found that removal of aqueous ${ }^{1} \mathrm{O}_{2}$ leads to the disappearance of DMPOX in ESR. Therefore, the generation of DMPOX is directly related to the oxidation of DMPO by plasma-produced aqueous ${ }^{1} \mathrm{O}_{2}$. This oxidation process and interactions between DMPO and chemical scavengers used in experiments can all be well explained by a proposed reaction mechanism. The revelation of interactions between aqueous ${ }^{1} \mathrm{O}_{2}$ and the spin trap DMPO shows that the observation of spectra of DMPOX in the ESR measurement can be regarded as a marker of high concentrations of plasma-produced ${ }^{1} \mathrm{O}_{2}$ in liquid. These results also prove the existence of interactions between spin traps and non-targeted plasma-produced reactive species in ESR experiments. Also, these results have offered a better understanding of the use of spin traps such as DMPO in the plasma-induced highly oxidative aqueous environment. Published by AIP Publishing. [http://dx.doi.org/10.1063/1.4986008]

\section{INTRODUCTION}

Recently, interactions between cold atmospheric plasma (CAP) and liquid have received more and more attention in the research field of plasma medicine. ${ }^{1-3}$ Aqueous reactive oxygen and nitrogen species (RONS) produced by CAP including $\mathrm{H}_{2} \mathrm{O}_{2}, \mathrm{OH}, \mathrm{O}_{2}^{--},{ }^{1} \mathrm{O}_{2}$, NO, and peroxynitrites have been found to play important roles in many biomedical effects of $\mathrm{CAP}^{4-6}$ Several quantitative investigations on these plasma-produced RONS have yielded some preliminary results to reveal the details of the chemical processes that happen during plasma treatment. According to recently reported research results, long-lived aqueous RONS including $\mathrm{H}_{2} \mathrm{O}_{2}, \mathrm{NO}_{2}{ }^{-}$, and $\mathrm{NO}_{3}{ }^{-}$have already been measured quantitatively using different methods such as fluorescent probes, ${ }^{7}$ liquid chromatography, ${ }^{8}$ and laser spectroscopy. ${ }^{9}$ For some short-lived species, electron spin resonance (ESR) spectroscopy is widely accepted as an effective method for measuring the concentrations of radical-related species such as ${ }^{\circ} \mathrm{OH},{ }^{1} \mathrm{O}_{2}$, and $\mathrm{O}_{2}^{-}$. Reuter et al. ${ }^{10-12}$ have done a series of ESR measurement studies on $\mathrm{OH}$ and $\mathrm{O}_{2}^{--}$produced by the argon plasma jet called kinpen in water. Their results have proved the existence of these short-lived species and also shown their quantitative generation rates. Similar work presented by $\mathrm{Wu}$ et al. ${ }^{13}$ reported the concentrations of $\mathrm{OH}$, ${ }^{1} \mathrm{O}_{2}$, and $\mathrm{O}_{2}^{--}$induced by a pure helium microplasma jet in water. Takamatsu et al. ${ }^{14}$ have compared the concentrations

\footnotetext{
${ }^{\text {a)} E l e c t r o n i c ~ a d d r e s s e s: ~ c h e n c h e n x j t u e e @ s i n a . c n ~ a n d ~ m k o n g @ o d u . e d u ~}$
}

of short-lived species including $\mathrm{OH}, \mathrm{NO}$, and ${ }^{1} \mathrm{O}_{2}$ produced by a plasma jet with different feeding gases. All these experimental results provide a lot of information about aqueous short-lived species produced by different plasmas.

Because of the high chemical activity of short-lived species, they can easily react with other components in liquid so that it is hard to detect them after plasma treatment. Therefore, chemical probes called spin traps are widely used in ESR experiments to react with these short-lived reactive species to generate stable and detectable radicals (spin trap adduct) during the whole treatment process. The different spectra of these spin trap adducts in the ESR can be used to identify the corresponding targeted species which are captured by spin traps. For example, DMPO (5,5-Dimethyl-1Pyrroline-N-Oxide) is a spin trap for measuring $\mathrm{OH}$ with a long history of use in ESR. ${ }^{15,16}$ The reaction between the ESR-silent DMPO and $\mathrm{OH}$ can generate the spin trap adduct of DMPO-OH, which has a specific spectrum of four peaks with a height ratio of $1: 2: 2: 1$. The appearance of this spectrum directly indicates the existence of $\mathrm{OH}$ in tested samples. Likewise, several other spin traps including TEMP, BMPO, TEMPONE-H, and DTCS have been used in measurements on other plasma-produced short-lived species..$^{10,13,14}$

However, plasma can generate multiple types of RONS in the treated solution, which is vividly called making the "cocktails" of reactive species. This situation makes it possible for the spin traps added into treated liquid to react with other non-target species during plasma treatment. These unexpected interactions would directly influence the effectiveness of ESR 
measurements on plasma-produced short-lived species. In fact, there are already some experiments that have provided several abnormal results when using spin traps such as DMPO. Liu et al. ${ }^{17}$ and Plimpton et al. ${ }^{18}$ have reported the observation of DMPOX, an oxidative form of DMPO, which appeared in air plasma treated liquid instead of the expected spin trap adduct of DMPO-OH. However, the sources/oxides that lead to this result and mechanisms of the interaction still remain unknown.

In this paper, we have first quantitatively measured the aqueous ${ }^{1} \mathrm{O}_{2}$ produced by a surface micro-discharge (SMD) air plasma device. When using spin trap DMPO to measure plasma-produced $\mathrm{OH}$, we observe that the spin trap adducts detected are DMPOX but not DMPO-OH. With a series of experiments by chemical scavengers, the source of oxidation on DMPO into DMPOX is confirmed to be ${ }^{1} \mathrm{O}_{2}$. Concluded from all phenomena observed in different experiments, the reaction mechanism of interactions between ${ }^{1} \mathrm{O}_{2}$ and DMPO is proposed.

\section{METHODS}

The SMD air plasma device is constructed by a specially designed printed circuit board (PCB). In Fig. 1, the schematic diagram of this device is shown with its geometric parameters. FR-4 fiberglass is the widely used material for the PCB dielectric substrate. In the designed SMD device, this material is also used as the dielectric layer with a thickness of $1.6 \mathrm{~mm}$. Copper/tin electrodes ( $43 \mu \mathrm{m}$ in thickness) are deposited onto the dielectric layer on both sides, respectively. The high voltage electrode is constructed as a $25.4 \mathrm{~mm}$ diameter disc. On the other side of the board, the grounded electrode is designed as hexagonal grids with the specified edge to edge spacing of $6.35 \mathrm{~mm}$ and the width of the hexagonal mesh of $0.76 \mathrm{~mm}$. When discharging, air surrounding the surface of the grounded electrode is excited to generate plasma. The discharging photograph is shown in Fig. 1(c).

A sinusoidal power supply with a peak-to-peak voltage in the range of $8.8-9.0 \mathrm{kV}$ at a frequency of $23 \mathrm{kHz}$ is applied on this device to generate plasma. Typical discharging waveforms of voltage and current are shown in Fig. 2 with the
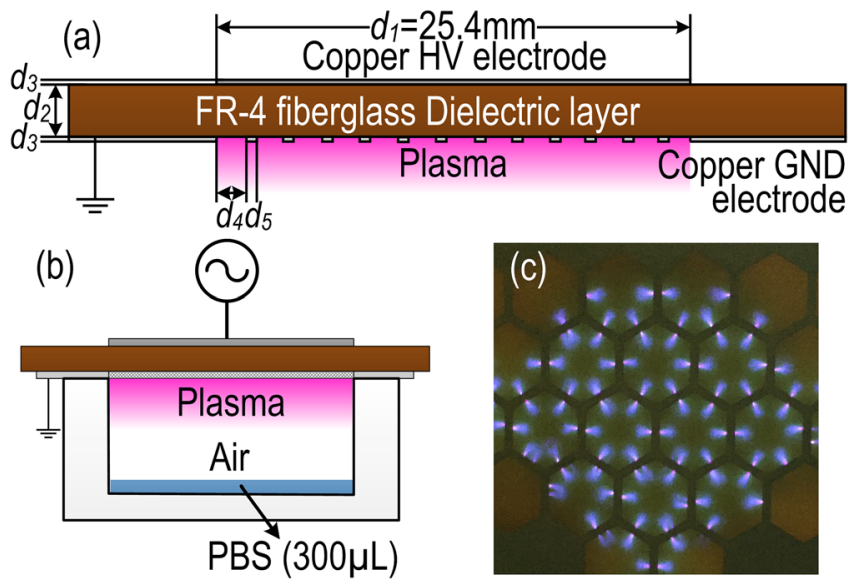

FIG. 1. (a) Schematic diagram of the PCB device. $\left(d_{2}=1.6 \mathrm{~mm}, \mathrm{~d}_{3}=43\right.$ $\mu \mathrm{m}, \mathrm{d}_{4}=6.35 \mathrm{~mm}$, and $\mathrm{d}_{5}=0.76 \mathrm{~mm}$ ). (b) Diagram of experiments on plasma treating PBS $(300 \mu \mathrm{l})$ in a closed well. (c) Photograph of discharge, viewed from the ground electrode grids.

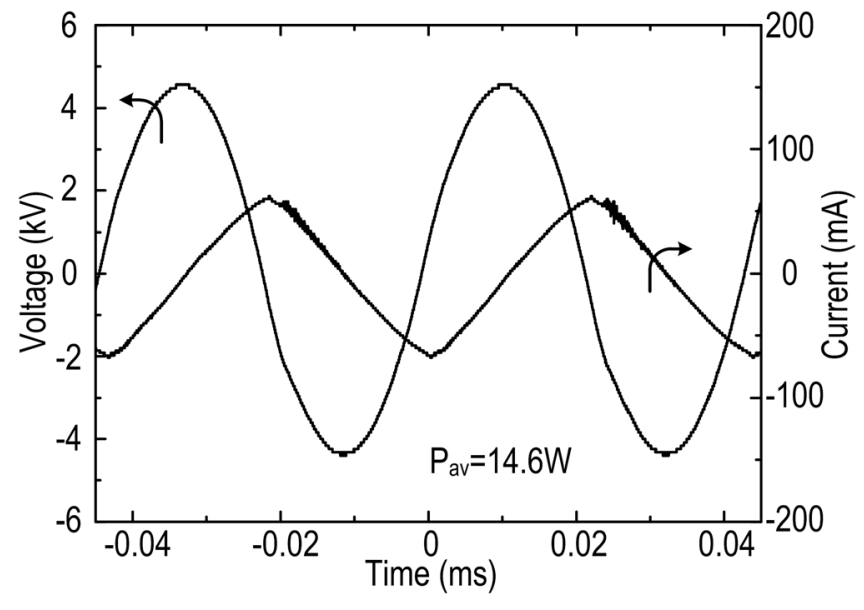

FIG. 2. Electrical waveforms of the voltage (left axis) and the current (right axis) of air plasma when discharging.

averaged power of $14.6 \mathrm{~W}$. The $300 \mu \mathrm{l}$ phosphate buffering solution (PBS) enclosed in a plastic well (standard 12-well plate) is treated for $60 \mathrm{~s}$ by the SMD plasma device, as shown in Fig. 1(b).

Electron spin resonance (ESR) spectroscopy is used to measure air plasma-produced ${ }^{1} \mathrm{O}_{2}$ and $\mathrm{OH}$ in PBS. Spin traps of TEMP (39.5 mM, 2,2,6,6-tetramethylpiperidine, Sigma) and DMPO (1-100 mM, Dojindo) are added into the solution before plasma treatment. During plasma treatment, these spin traps are expected to keep reacting with ${ }^{1} \mathrm{O}_{2}$ and $\mathrm{OH}$ to generate stable spin trap adducts of TEMPO and DMPO-OH, respectively. A Bruker EMX + ESR spectrometer is used to carry out all these experiments. ESR parameters are set as follows: sweep range, $100 \mathrm{G}$; microwave power, $2 \mathrm{~mW}$; time constant, $0.01 \mathrm{~s}$; and center magnetic field, 3513 G. Spectra obtained from the ESR spectrometer are converted into absolute concentrations of spin trap adducts by a standard curve calibrated from the stable radicals of TEMPO: Several chemical scavengers have also been used in experiments including D-Mannitol (Sigma), sodium azide $\left(\mathrm{NaN}_{3}\right.$, Sigma), and Trolox (6-Hydroxy-2,5,7,8-tetramethylchroman-2-carboxylic acid, Sigma). Their concentrations vary according to different experimental demands, which will be discussed in detail in Sec. III.

\section{RESULTS AND DISCUSSION}

\section{A. Measurement on ${ }^{1} \mathrm{O}_{2}$ and $\mathrm{OH}$ in air plasma treated PBS}

The spin trap of TEMP is used to capture plasmaproduced ${ }^{1} \mathrm{O}_{2}$ in PBS. TEMP in liquid can be oxidized by ${ }^{1} \mathrm{O}_{2}$ through an oxygen addition reaction occurring on the nitrogen of TEMP, as shown in Fig. 3(a). A stable radical of TEMPO is generated through this trapping reaction, showing a three-peak spectrum obtained by ESR spectroscopy. Figure 3(a) shows the TEMPO spectrum obtained from PBS treated by SMD plasma for $60 \mathrm{~s}$. The hyperfine coupling constant of 17.17 indicates that this spectrum is of the standard TEMPO without any other radicals mixed.

Quantitative concentrations of TEMPO are presented by a time curve (red curve) in Fig. 3(b). The total plasma 

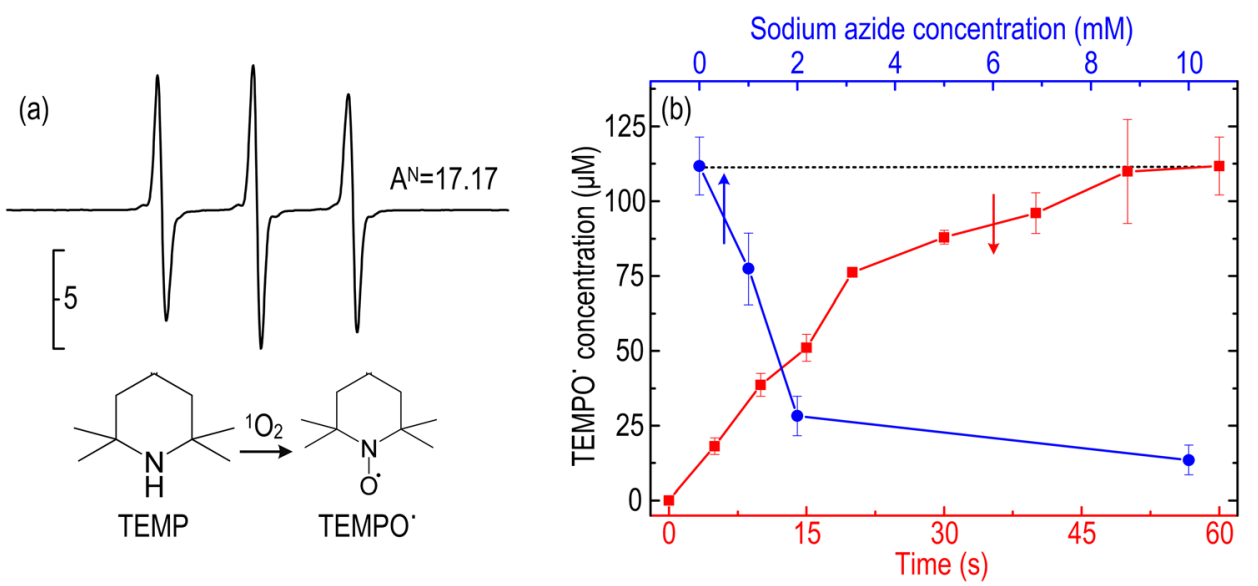

FIG. 3. Measurement on aqueous ${ }^{1} \mathrm{O}_{2}$ induced by air SMD plasma in PBS. (a) The spectrum of the spin trap adduct of TEMPO obtained with $60 \mathrm{~s}$ plasma treatment, with the hyperfine coupling constant and trapping reaction shown as well. (b) Time curve (red) of concentrations of TEMPO during $60 \mathrm{~s}$ plasma treatment and the chemical scavenger test (blue curve) on the specificity of TEMP capturing ${ }^{1} \mathrm{O}_{2}$. The blue curve shows the inhibition of TEMP reacting with ${ }^{1} \mathrm{O}_{2}$ to generate TEMPO by the increasing concentration of sodium azide (the scavenger to ${ }^{1} \mathrm{O}_{2}$ ), which indicates that most TEMPO detected from ESR (red curve) comes from the effective capture of ${ }^{1} \mathrm{O}_{2}$ but not from other species. All samples with different sodium azide concentrations are treated for $60 \mathrm{~s}$ by plasma.

treatment time is $60 \mathrm{~s}$. It is obvious to find that the concentration of TEMPO is kept increasing along with plasma treatment time. Considering that there is no generation pathway for ${ }^{1} \mathrm{O}_{2}$ by reaction in liquid, ${ }^{19,20}$ gaseous ${ }^{1} \mathrm{O}_{2}$ generated in plasma is the only source for these captured aqueous ${ }^{1} \mathrm{O}_{2}$. This monotonically increasing time curve of TEMPO in Fig. 3(b) indicates SMD air plasma acting as a stable supply for the aqueous ${ }^{1} \mathrm{O}_{2}$ in PBS. With $60 \mathrm{~s}$ plasma treatment, the maximum concentration of TEMPO can reach $110 \mu \mathrm{M} . \mathrm{O}_{2}$ in air that is involved in the discharge process is the reason for the effective generation of ${ }^{1} \mathrm{O}_{2}$ in plasma.

On the other hand, since ESR measurements on shortlived species are carried out indirectly through spin traps, the specificity of these spin traps can directly influence the measurement results. For example, as the literature reported, ${ }^{21}$ this trapping reaction of TEMP to ${ }^{1} \mathrm{O}_{2}$ can be influenced by aqueous $\mathrm{O}$ and $\mathrm{O}_{3}$ because they can also react with TEMP to generate the same spin trap adducts of TEMPO. TEMPO obtained from plasma treated liquid may also be derived from plasmaproduced aqueous $\mathrm{O}$ and $\mathrm{O}_{3}$. Therefore, TEMPO results in Fig. 3 need to be tested by chemical scavengers to verify the exact species that TEMP captured. We add sodium azide $\left(\mathrm{NaN}_{3}\right)$, chemical scavenger to ${ }^{1} \mathrm{O}_{2}$, together with TEMP into plasma treated liquid, in order to prevent ${ }^{1} \mathrm{O}_{2}$ from being captured by TEMP. If the addition of sodium azide inhibits the generation of TEMPO; it shows that TEMP indeed captures ${ }^{1} \mathrm{O}_{2}$ rather than other species. As the blue curve in Fig. 3(b) shows, $2 \mathrm{mM}$ sodium azide added into plasma treated liquid leads to only $25 \%$ TEMPO measured in ESR compared to the no sodium azide case (all treated by plasma for $60 \mathrm{~s}$ ). With the increase in sodium azide concentrations, it is observed that $10 \mathrm{mM}$ sodium azide can remove most of the ${ }^{1} \mathrm{O}_{2}(83 \%)$, which proves that the TEMPO is indeed from the effective capture of ${ }^{1} \mathrm{O}_{2}$ by TEMP.

As mentioned above, spin trap DMPO is used to test the OH produced by air SMD plasma in PBS. DMPO reacts with $\mathrm{OH}$ to form the spin trap adduct of DMPO-OH with a fourpeak spectrum with a height ratio of 1:2:2:1. However, in our ESR experiments using DMPO, the standard four-peak spectrum of DMPO-OH is not appeared. Instead, as shown in Fig. 4(a), a seven-peak spectrum is observed. This spectrum is appeared at the same center magnetic field of $3513 \mathrm{G}$ to DMPO-OH under the same microwave power. Fitted with the simulation spectrum using the SpinFit software, the hyperfine coupling constants of this spectrum are $\mathrm{A}^{\mathrm{N}}=7.26$ and $\mathrm{A}^{\mathrm{H}}$ $=4.04$. According to reported literatures, ${ }^{22-24}$ this spectrum is from DMPOX, an oxidized form of DMPO, without any other spectra mixed. The chemical structure of DMPOX is also shown in Fig. 4(a) together with the origin spin trap DMPO and the spin trap adduct of DMPO-OH. It can be found that the difference between DMPOX and DMPO-OH is that the $-\mathrm{OH}$ functional group at the 2 nd position of pyrroline is replaced by an oxygen atom. This difference in the structure is the reason that these two spin trap adducts show totally different spectra in ESR the measurement.

In Fig. 4(b), we try to find whether the appearance of DMPOX is determined by the DMPO concentration or plasma treatment time. It is found that DMPOX can all appear when the DMPO concentration varies between the recommended concentrations from $1 \mathrm{mM}$ to $100 \mathrm{mM}$. With 60 s plasma treatment, spectra obtained are all of DMPOX without other spectra appeared. The results in Fig. 4(b) show that the concentrations of DMPOX vary nonlinearly both along with DMPO concentrations and plasma treatment time. In the first 20-30 s, concentrations of DMPOX increase when the DMPO concentration increases from $1 \mathrm{mM}$ to $10 \mathrm{mM}$. However, it starts to drop when DMPO is more than $50 \mathrm{mM}$ (up to $100 \mathrm{mM}$ ). This shows that the excess of DMPO can reduce the generation of DMPOX. On the other hand, with more than 30 s treatment, concentrations of DMPOX start to decrease in all cases of different DMPO concentrations. Similar phenomena that longer exposure time on DMPO containing samples leads to lower DMPOX concentrations are observed in the UVA irradiated solution ${ }^{25}$ and metal-related reactions. ${ }^{26}$ The decrease can be explained by the dimerization of DMPOX at high concentrations.

The observation of DMPOX instead of DMPO-OH shows an unexpected oxidation process occurring in the air 

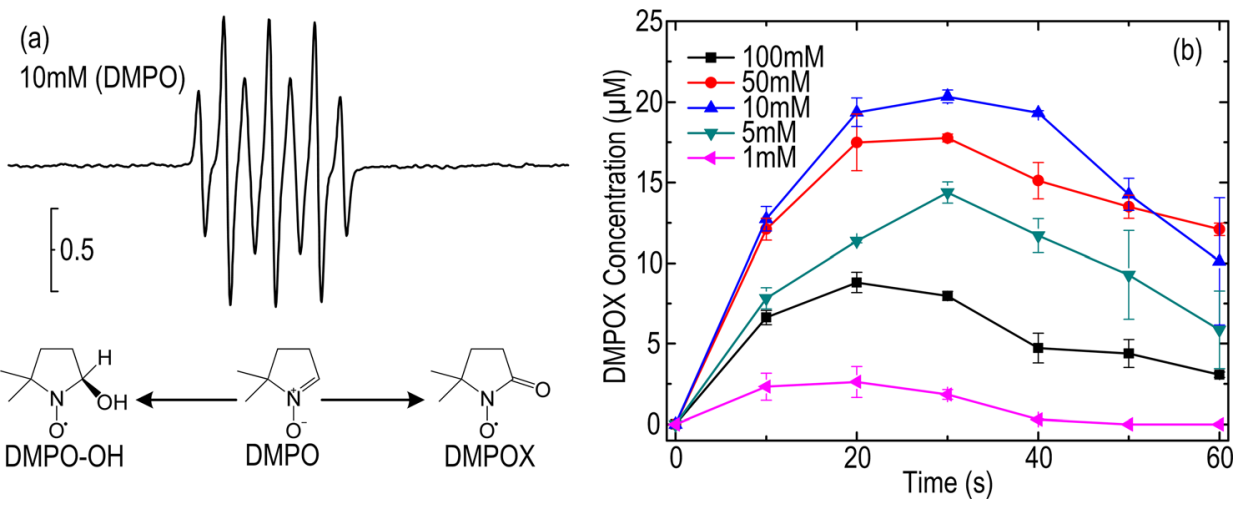

FIG. 4. Observation of DMPOX when measuring $\mathrm{OH}$ in the plasma treated solution. (a) The spectrum of spin trap adduct DMPOX obtained with $20 \mathrm{~s}$ plasma treatment and $10 \mathrm{mM}$ DMPO added into the sample. The hyperfine coupling constants of DMPOX are $\mathrm{A}^{\mathrm{N}}=7.26$ and $\mathrm{A}^{\mathrm{H}}=4.04$. Differences on the chemical structure of DMPO, DMPO-OH, and DMPOX are shown as well. (b) Time curves of concentrations of DMPOX during $60 \mathrm{~s}$ plasma treatment with different DMPO concentrations added into plasma treated samples. plasma treated PBS. DMPOX has also been found to appear in other air plasma treated samples. ${ }^{17,18}$ Therefore, the revelation on the oxidation process of DMPO can offer a clearer view on the chemistry in the high oxidative solutions treated by air plasma.

\section{B. Tests on sources of oxidation of DMPO}

No satisfactory explanation about the original oxides that oxidize DMPO into DMPOX has been reported yet. In different experiments, several chemicals including $\mathrm{HAuCl}_{4}{ }^{26}$ ${ }^{1} \mathrm{O}_{2}{ }^{27} \mathrm{ClO}_{2}{ }^{28}$ and $\mathrm{O}_{3}{ }^{29}$ have been proposed to complete this process. Some researchers reported that DMPOX is oxidized from DMPO-OH but not DMPO itself. ${ }^{30,31}$ However, it is unlikely the case in our plasma system. We use the scavenger for $\mathrm{OH}$ radicals, D-Mannitol, to inhibit plasma-produced $\mathrm{OH}$ in liquid in order to prevent the generation of DMPO-OH. The addition of D-Mannitol has not scavenged all DMPOX when the DMPOX concentrations become stable, as shown in Fig. 5(a). In Fig. 5(b), the spectrum pattern of DMPOX is also not influenced by the highest D-Mannitol concentration of $320 \mathrm{mM}$. These results show that the oxidation of DMPO into DMPOX is related to $\mathrm{OH}$ in the solution, but it is not initialized by $\mathrm{OH}$. There are still other plasma-produced oxides that oxidize DMPO into DMPOX directly. This process is not started from DMPO-OH but from DMPO.

Since ${ }^{1} \mathrm{O}_{2}$ has already been measured to be existed in plasma treated liquid by using the spin trap of TEMP, ${ }^{1} \mathrm{O}_{2}$ as another possible oxide to form DMPOX has also been tested. Similar to D-Mannitol, varying concentrations of sodium azide are added into PBS together with $10 \mathrm{mM}$ DMPO. It is found that sodium azide can much more effectively reduce the intensities of the DMPOX spectrum than D-Mannitol, as shown in Fig. 6(a). Only $10 \mathrm{mM}$ sodium azide leads to no any spectra tested in ESR at all. This result is well agreed with the results shown in Fig. 3(b) that $10 \mathrm{mM}$ sodium azide can also effectively inhibit the capture of ${ }^{1} \mathrm{O}_{2}$ by TEMP. Additionally, we have also tested the addition of sodium azide into samples with different concentrations of DMPO. The addition of sodium azide can reduce DMPOX concentrations in all three cases directly, as shown in Fig. 6(b) These results have proved the possibility that the oxidation of DMPOX is a ${ }^{1} \mathrm{O}_{2}$ initialized process.

Chemical scavengers added into solution can remove the corresponding aqueous RONS. As analyzed above, aqueous ${ }^{1} \mathrm{O}_{2}$ directly comes from those generated inside plasma. Therefore, if ${ }^{1} \mathrm{O}_{2}$ indeed acts as the direct oxide to DMPO, the reduction in the supply of gaseous ${ }^{1} \mathrm{O}_{2}$ should also result in the decrease in the DMPOX concentration. As our SMD device generates air plasma, we use two methods to influence gaseous ${ }^{1} \mathrm{O}_{2}$ to diffuse into liquid. Putting the same volume of treated liquid in an open environment rather than a closed well would lead to side loss of plasma generated ${ }^{1} \mathrm{O}_{2}$ in surrounding ambient air, which reduces the amount of ${ }^{1} \mathrm{O}_{2}$ diffusing into liquid, as shown in Fig. 7. Meanwhile, putting the treated liquid into a ventilating system with disturbance on discharging air can further blow away plasma generated reactive species before they enter into the treated solution. In Fig. 7, we have compared ESR measurements on DMPO containing samples $(10 \mathrm{mM})$ treated by air plasma in these three cases. The results show that the reduction in supply of gaseous ${ }^{1} \mathrm{O}_{2}$ can also significantly reduce concentrations of DMPOX in downstream PBS. There are only 9.6\% DMPOX detected in the Open case compared to the Close case. In the Open + Flow case, there is no effective spectrum observed from the treated sample. Together with the chemical
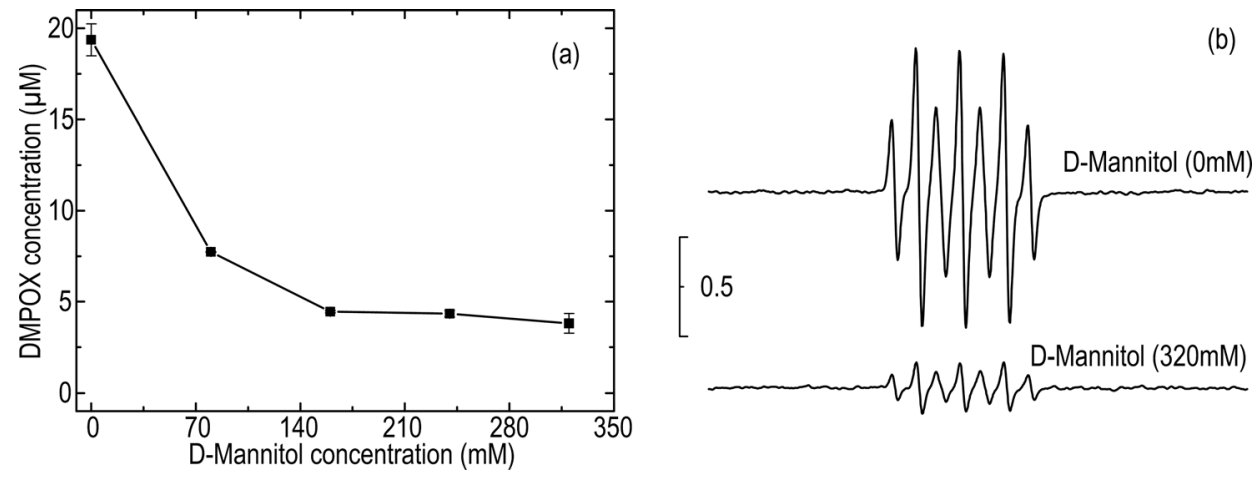

FIG. 5. Influences on DMPOX from the addition of D-Mannitol to scavenge $\mathrm{OH}$ in the plasma treated solution. (a) Variation on D-Mannitol concentrations to reduce DMPOX concentrations. (b) No influence has been observed on the spectra patterns of DMPOX even with the highest DMannitol concentrations of $320 \mathrm{mM}$. Hyperfine coupling constants of the two spectra are $\mathrm{A}^{\mathrm{N}}=7.26$ and $\mathrm{A}^{\mathrm{H}}=4.04$ for the upper one and $\mathrm{A}^{\mathrm{N}}=7.26$ and $\mathrm{A}^{\mathrm{H}}=4.03$ for the lower one. 

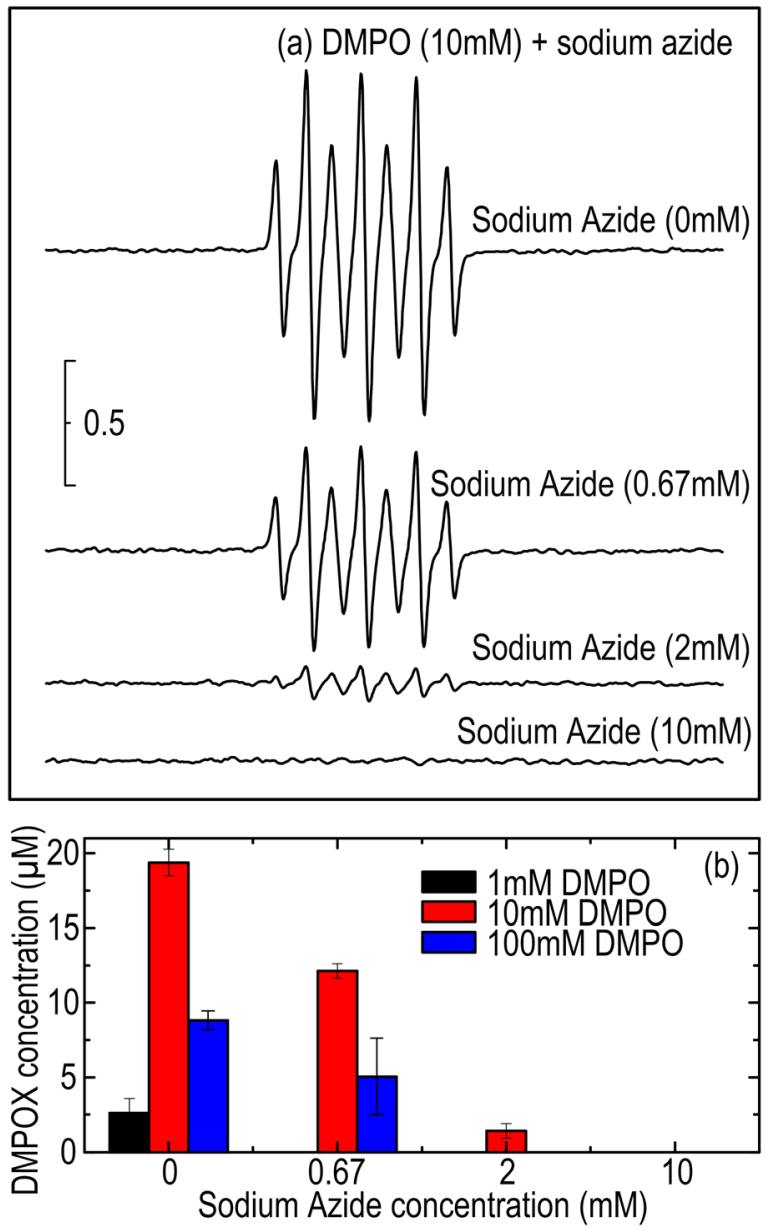

FIG. 6. Tests on the impacts on (a) spectra and (b) concentrations of DMPOX by using different concentrations of sodium azide, ${ }^{1} \mathrm{O}_{2}$ scavengers. All tests are done with $20 \mathrm{~s}$ plasma treatment. The concentration of DMPO in (a) is $10 \mathrm{mM}$. Hyperfine coupling constants of spectra in (b) are $\mathrm{A}^{\mathrm{N}}=7.26, \quad \mathrm{~A}^{\mathrm{H}}=4.04 \quad(0 \mathrm{mM}) ; \quad \mathrm{A}^{\mathrm{N}}=7.25, \quad \mathrm{~A}^{\mathrm{H}}=4.03 \quad(0.67 \mathrm{mM}) ; \quad$ and $\mathrm{A}^{\mathrm{N}}=7.26, \mathrm{~A}^{\mathrm{H}}=4.02(2 \mathrm{mM})$.

scavenger of sodium azide tests in Fig. 6, all these results indicate the fact that ${ }^{1} \mathrm{O}_{2}$ is the most possible oxide of DMPO into DMPOX.

Also from Figs. 6 and 7, it can be seen that when all DMPOX disappears by both scavengers and gaseous ${ }^{1} \mathrm{O}_{2}$ supply, the spectrum of DMPO-OH still does not appear. This proves that there is almost no $\mathrm{OH}$ radicals generated in air plasma treated PBS. Considering the $17.5 \mathrm{~mm}$ air gap between the plasma device and treated sample surface, this is agreed with previous studies that $\mathrm{OH}$ can hardly diffuse into the downstream solution treated by air plasma. ${ }^{17,20}$

\section{Interaction between DMPO and ${ }^{1} \mathrm{O}_{2}$ and oxidation mechanism of DMPO}

Another interesting phenomenon about DMPOX has been observed as well. The addition of Trolox, a phenolic compound, into DMPO containing PBS treated by air plasma has led to the appearance of DMPO-OH but not DMPOX, as shown in Fig. 8. In Fig. 8(a), the intensity of DMPO-OH spectra kept increasing when more Trolox is added with the same concentration of DMPO $(100 \mathrm{mM})$. Concentrations of DMPO-OH do not rely on DMPOX when the concentration
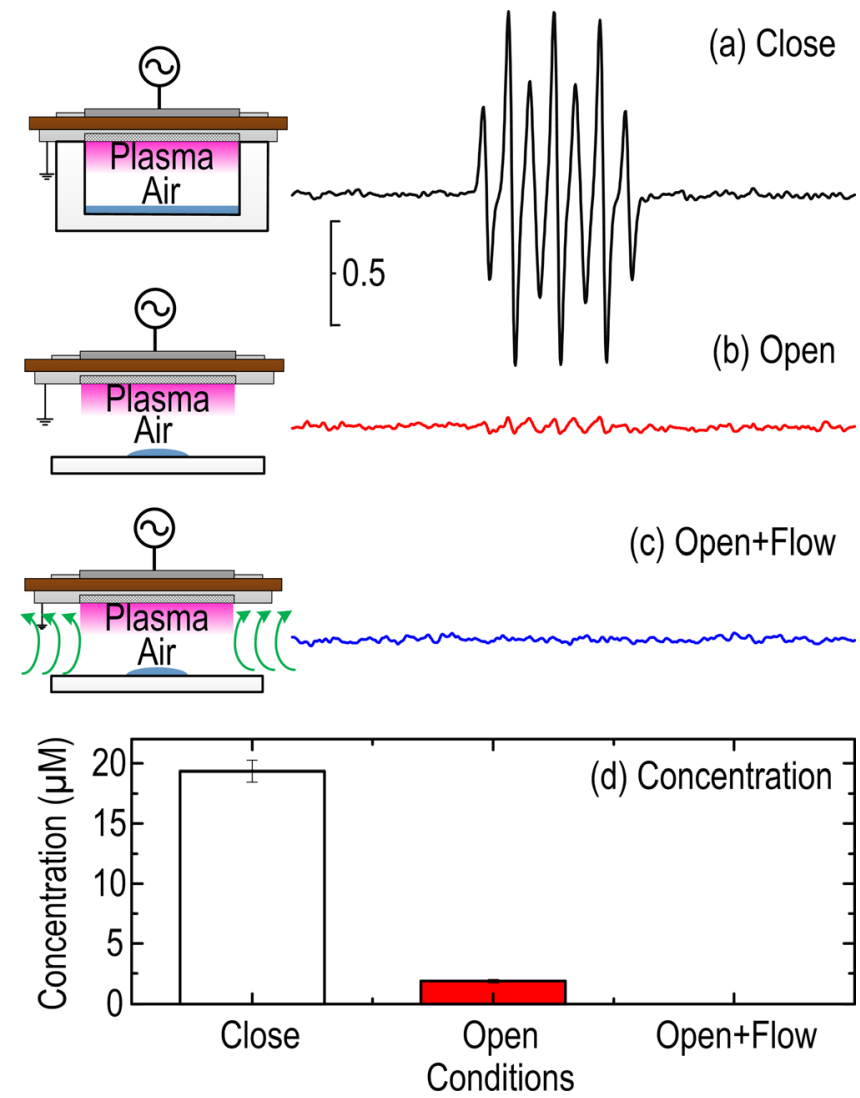

FIG. 7. Influences on DMPOX in plasma treated PBS from disturbance on the supply of gaseous ${ }^{1} \mathrm{O}_{2}$ generated in plasma. Three forms of treatments are shown as (a) samples in a closed well; (b) samples on an open plate; and (c) samples on an open plate and be put into a ventilating system with air flow. Spectra are shown in each sub figures with the hyperfine coupling constants of (a) $\mathrm{A}^{\mathrm{N}}=7.26, \quad \mathrm{~A}^{\mathrm{H}}=4.04$, (b) $\mathrm{A}^{\mathrm{N}}=7.25$, and $\mathrm{A}^{\mathrm{H}}=4.04$. Concentrations of DMPOX obtained in each case are shown in (d). DMPO concentrations in all cases are set as $10 \mathrm{mM}$.

of $10 \mathrm{mM}$ of DMPO which is higher than that of DMPOX does not lead to more generation of DMPO-OH (Fig. 8). This situation reveals that the appearance of DMPO-OH in this case is a process depending on the addition of Trolox but not from plasma-produced $\mathrm{OH}$ in the solution.

Similar transfer of DMPOX to DMPO-OH by Trolox has also been observed in the oxidation of DMPO by photodynamics-produced ${ }^{1} \mathrm{O}_{2}$ experiments by Ueda et al. ${ }^{25}$ According to the reaction mechanism they proposed, phenolic compounds including Trolox act as electron donors for an intermediate from oxidation of DMPO by ${ }^{1} \mathrm{O}_{2}$ to generate DMPO-OH. This reaction interrupts the origin pathway for this intermediate to be oxidized into DMPOX. Well explained by this proposed mechanism, phenomena we observed in Fig. 8 have proved that DMPOX generated in air plasma treated PBS is mostly from oxidation of DMPO by ${ }^{1} \mathrm{O}_{2}$. The reason for DMPOX has not been observed from other plasma jet treated solutions can also be explained by there are much less aqueous ${ }^{1} \mathrm{O}_{2}$ be generated in those noble gas feeding plasma jets ${ }^{10,13,14}$ than in air plasma (Fig. 3). Therefore, the revelation of interactions between aqueous ${ }^{1} \mathrm{O}_{2}$ and spin trap DMPO shows that the observation of DMPOX in the ESR measurement can be regarded as a marker of high concentrations of ${ }^{1} \mathrm{O}_{2}$ in plasma treated liquid. 



FIG. 8. Interactions between DMPO and Trolox to generate DMPO-OH with $20 \mathrm{~s}$ plasma treatment. (a) Spectra obtained in DMPO + Trolox containing samples treated by plasma for $20 \mathrm{~s}$. The DMPO concentration in samples is set to be $100 \mathrm{mM}$, with variations in Trolox concentrations from $0 \mathrm{mM}$ to $4.5 \mathrm{mM}$. Hyperfine coupling constants of spectra are $\quad \mathrm{A}^{\mathrm{N}}=7.26, \quad \mathrm{~A}^{\mathrm{H}}=4.04 \quad(0 \mathrm{mM}$ Trolox $) ; \mathrm{A}^{\mathrm{N}}=14.86, \mathrm{~A}^{\mathrm{H}}=14.61(1 \mathrm{mM}$ Trolox); $\mathrm{A}^{\mathrm{N}}=14.90, \mathrm{~A}^{\mathrm{H}}=14.77(3 \mathrm{mM}$ Trolox); and $\mathrm{A}^{\mathrm{N}}=14.92, \mathrm{~A}^{\mathrm{H}}=14.68$ (4.5 mM Trolox). Different intensity scales of DMPOX and DMPO-OH in (a) are also marked. (b) Concentrations of DMPOX and DMPO-OH with both variations on DMPO and Trolox concentrations.
Concluded from all results of tests we have done on the appearance of DMPOX from Fig. 5 to Fig. 8, a reaction mechanism of the generation of DMPOX and influences from D-Mannitol, sodium azide, and Trolox is proposed in Fig. 9. DMPO in the solution is first oxidized by ${ }^{1} \mathrm{O}_{2}$ to generate the intermediate of DMPO-OO' with two oxygen atoms added onto the $\mathrm{C}=\mathrm{N}$ bond of DMPO. The outer oxygen in DMPO-OO is easy to capture an $\mathrm{H}^{+}$in the solution and then become the important intermediate $\mathrm{DMPO}^{\oplus}{ }_{-} \mathrm{OOH}$. Because of the captured $\mathrm{H}^{+}$, this intermediate $\mathrm{DMPO}^{\oplus}-\mathrm{OOH}$ is highly oxidative and needs a negative charge to be electrically balanced. In treatment without other chemicals added into the solution, these $\mathrm{DMPO}^{\oplus}{ }_{-} \mathrm{OOH}$ can continue oxidizing, making DMPO to form DMPOX that has the seven-peak spectra through Pathway 1. As analyzed above, excess DMPO can react with DMPOX to generate an ESR-silent Product I so that the concentration is higher than $10 \mathrm{mM}$ of DMPO in PBS leads to drop in the DMPOX concentration in previous experiments.

For $\mathrm{OH}$ radicals that do not take part in Pathway 1, the use of $\mathrm{OH}$ scavenger, D-Mannitol, would not function to remove $\mathrm{OH}$ in the generation process of DMPOX. Instead, D-Mannitol added into the solution can still act as the reductant to offer electrons for $\mathrm{DMPO}^{\oplus}-\mathrm{OOH}$ to generate another
ESR-silent Product II through Pathway 2. The result from Fig. 5 that it takes $150 \mathrm{mM}$ D-Mannitol to make the DMPOX concentration stable indicates this reaction to be a slow one. The other part of $\mathrm{DMPO}^{\oplus}-\mathrm{OOH}$ would still go through Pathway 1 to generate DMPOX. Therefore, this is the reason why the addition of D-Mannitol could not totally scavenge the concentrations of DMPOX in Fig. 5(a).

Phenolic compound Trolox can also function as the electron donor for the intermediate $\mathrm{DMPO}^{\oplus}{ }_{-} \mathrm{OOH}$. The addition of Trolox leads to $\mathrm{DMPO}^{\oplus}-\mathrm{OOH}$ to turn into Pathway 3. The difference is the reaction between $\mathrm{DMPO}^{\oplus}-\mathrm{OOH}$ and Trolox, which would generate DMPO-OH that shows the four-peak spectrum [Fig. 8(a)]. Only $1 \mathrm{mM}$ Trolox is enough to inhibit the appearance of DMPOX. Compared to the high D-Mannitol concentration, it needs to reduce the DMPOX concentration [Fig. 5(a)], and this result reveals that reaction between $\mathrm{DMPO}^{\oplus_{-}} \mathrm{OOH}$ and Trolox is much faster than reaction with D-Mannitol. Also because Trolox functions as the interrupter to Pathway 1, the concentration of generated DMPO-OH is relied on that of Trolox as mentioned above. The proposed mechanism diagram shown in Fig. 9 can explain all phenomena observed from our experiments. However, more experiments as to determine the identities of Product I and Product II are still needed.

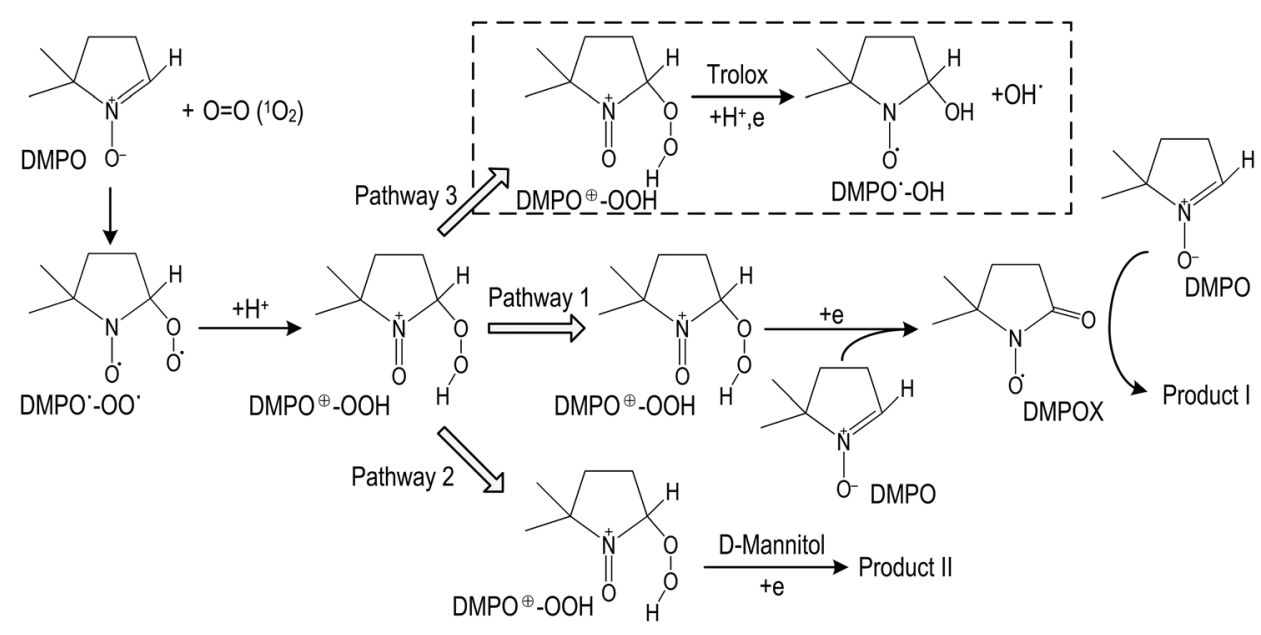

FIG. 9. Mechanism of the oxidation of DMPO initiated by ${ }^{1} \mathrm{O}_{2}$ into different pathways by different chemicals acting as electron donors. 


\section{CONCLUSIONS}

In this study, electron spin resonance spectroscopy is used to quantitatively measure aqueous ${ }^{1} \mathrm{O}_{2}$ and $\mathrm{OH}$ produced by air SMD plasma in PBS. By using the spin trap of TEMP, the concentration of the spin trap adduct of TEMPO of plasma-produced ${ }^{1} \mathrm{O}_{2}$ is measured to be $110 \mu \mathrm{M}$ with $60 \mathrm{~s}$ plasma treatment. However, when measuring $\mathrm{OH}$ using DMPO, the spectrum of DMPOX instead of typical DMPO$\mathrm{OH}$ has appeared in all treated samples with different DMPO concentrations. A series of test experiments with several scavengers shows that the DMPOX comes from the oxidation of DMPO by ${ }^{1} \mathrm{O}_{2}$ and no $\mathrm{OH}$ is generated in PBS by air plasma. In addition, a phenolic compound, Trolox, added into the solution with DMPO leads to the appearance of DMPO-OH.

Consequently, interactions between DMPO and plasmaproduced ${ }^{1} \mathrm{O}_{2}$ are summarized from all phenomena observed about DMPOX. The mechanism of the oxidation process from DMPO to DMPOX has also been proposed. Initialized by ${ }^{1} \mathrm{O}_{2}$, the oxidation of DMPO would generate a series of intermediates. Intermediate $\mathrm{DMPO}^{\oplus}-\mathrm{OOH}$ can keep reacting with other DMPO to form DMPOX. With the addition of other chemicals, this intermediate can be transferred into different resultants as DMPO-OH or other ESR-silent products. The proposed oxidation mechanism of DMPO by ${ }^{1} \mathrm{O}_{2}$ can well explain all phenomena reported. The revelation of interactions between aqueous ${ }^{1} \mathrm{O}_{2}$ and spin trap DMPO shows that the observation of DMPOX in the ESR measurement can be regarded as a marker of high concentrations of ${ }^{1} \mathrm{O}_{2}$ in plasma treated liquid. This interaction proves the existence of interference on spin traps used in ESR from other nontargeted plasma-produced components in liquid. Also, these results have offered a better understanding of the use of spin traps such as DMPO in a plasma induced highly oxidative aqueous environment.

\section{ACKNOWLEDGMENTS}

The authors are grateful to the Chinese Scholarship Council for their support for the research project of "Reaction chemistry in biological media under treatment by gas plasmas, and the supports from Old Dominion University."

${ }^{1}$ H. Jablonowski and T. von Woedtke, Clin. Plasma Med. 3, 42 (2015).

${ }^{2}$ P. J. Bruggeman, M. J. Kushner, B. R. Locke, J. G. E. Gardeniers, W. G. Graham, D. B. Graves, R. C. H. M. Hofman-Caris, D. Maric, J. P. Reid, E. Ceriani, D. Fernandez Rivas, J. E. Foster, S. C. Garrick, Y. Gorbanev, S. Hamaguchi, F. Iza, H. Jablonowski, E. Klimova, J. Kolb, F. Krcma, P.
Lukes, Z. Machala, I. Marinov, D. Mariotti, S. M. Thagard, D. Minakata, E. C. Neyts, J. Pawlat, Z. L. Petrovic, R. Pflieger, S. Reuter, D. C. Schram, S. Schroter, M. Shiraiwa, B. Tarabova, P. A. Tsai, J. R. R. Verlet, T. von Woedtke, K. R. Wilson, K. Yasui, and G. Zvereva, Plasma Sources Sci. Technol. 25, 053002 (2016).

${ }^{3}$ M. G. Kong, G. Kroesen, G. Morfill, T. Nosenko, T. Shimizu, J. van Dijk, and J. L. Zimmermann, New J. Phys. 11, 115012 (2009).

${ }^{4}$ D. B. Graves, J. Phys. D: Appl. Phys. 45, 263001 (2012).

${ }^{5}$ D. B. Graves, Plasma Processes Polym. 11, 1120 (2014).

${ }^{6}$ S. J. Kim and T. H. Chung, Sci. Rep. 6, 20332 (2016).

${ }^{7}$ P. Lukes, E. Dolezalova, I. Sisrova, and M. Clupek, Plasma Sources Sci. Technol. 23, 015019 (2016).

${ }^{8}$ M. Sahni and B. R. Locke, Ind. Eng. Chem. Res. 45, 5819 (2006).

${ }^{9}$ P. Rumbach, D. M. Bartels, R. M. Sankaran, and D. B. Go, Nat. Commun. 6, 7248 (2015).

${ }^{10}$ H. Tresp, M. U. Hammer, J. Winter, K.-D. Weltmann, and S. Reuter, J. Phys. D: Appl. Phys. 46, 435401 (2013).

${ }^{11}$ H. Tresp, M. U. Hammer, J. Winter, K.-D. Weltmann, and S. Reuter, Plasma Med. 3, 45 (2013).

${ }^{12}$ H. Jablonowski, R. Bussiahn, M. U. Hammer, K.-D. Weltmann, T. von Woedtke, and S. Reuter, Phys. Plasmas 22, 122008 (2015).

${ }^{13}$ H. Wu, P. Sun, H. Feng, H. Zhou, R. Wang, Y. Liang, J. Lu, W. Zhu, J. Zhang, and J. Fang, Plasma Processes Polym. 9, 417 (2012).

${ }^{14}$ T. Takamatsu, K. Uehara, Y. Sasaki, H. Miyahara, Y. Matsumura, A. Iwasawa, N. Ito, T. Azuma, M. Kohno, and A. Okino, RSC Adv. 4, 39901 (2014).

${ }^{15}$ E. G. Janzen and J. I.-P. Liu, J. Magn. Reson. 9, 510 (1973).

${ }^{16}$ G. R. Buettner and L. W. Oberley, Biochem. Biophys. Res. Commun. 83 69 (1978).

${ }^{17}$ D. X. Liu, Z. C. Liu, C. Chen, A. J. Yang, D. Li, M. Z. Rong, H. L. Chen, and M. G. Kong, Sci. Rep. 6, 23737 (2016).

${ }^{18}$ S. R. Plimpton, M. Golkowski, D. G. Mitchell, C. Austin, S. S. Eaton, G. R. Eaton, C. Golkowski, and M. Voskuil, Biotechnol. Bioeng. 110, 1936 (2013).

${ }^{19}$ C. Chen, D. X. Liu, Z. C. Liu, A. J. Yang, H. L. Chen, G. Shama, and M. G. Kong, Plasma Chem. Plasma Process. 34, 403 (2014).

${ }^{20}$ Z. C. Liu, D. X. Liu, C. Chen, D. Li, A. J. Yang, M. Z. Rong, H. L. Chen, and M. G. Kong, J. Phys. D: Appl. Phys. 48, 495201 (2015).

${ }^{21}$ Y. Gorbanev, D. O'Connell, and V. Chechik, Chem.-Eur. J. 22, 3496 (2016).

${ }^{22}$ R. A. Floyd and L. M. Soong, Biochem. Biophys. Res. Commun. 74, 79 (1977).

${ }^{23}$ S. D. Stan and M. A. Daeschel, J. Agric. Food Chem. 53, 4906 (2005).

${ }^{24}$ J. M. Fontmorin, R. C. B. Castillo, W. Z. Tang, and M. Sillanpaa, Water Res. 99, 24 (2016).

${ }^{25}$ J.-I. Ueda, K. Takeshita, S. Matsumoto, K. Yazaki, M. Kawaguchi, and T. Ozawa, Photochem. Photobiol. 77, 165 (2003).

${ }^{26}$ A. Nakajima, Y. Ueda, N. Endoh, K. Tajima, and K. Makino, Can. J. Chem. 83, 1178 (2005).

${ }^{27}$ P. Bilski, K. Reszka, M. Bilska, and C. F. Chignell, J. Am. Chem. Soc. 118, 1330 (1996)

${ }^{28}$ T. Ozawa, Y. Miura, and J.-I. Ueda, Free Radicals Biol. Med. 20, 837 (1996).

${ }^{29}$ S. Horikoshi, Y. Wada, N. Watanabe, H. Hidaka, and N. Serpone, New J. Chem. 27, 1216 (2003).

${ }^{30}$ S. V. Verstraeten, S. Lucangioli, and M. Galleano, Inorg. Chim. Acta 362, 2305 (2009).

${ }^{31}$ C. M. Jones and M. J. Burkitt, J. Chem. Soc., Perkin Trans. 2, 2044 (2002). 